\title{
PCR-based DGGE Identification of Bacteria Present in Pasteurised South African Fruit Juices
}

\author{
W. Duvenage ${ }^{1}$, P.A. Gouws ${ }^{2}$ and R.C. Witthuhn ${ }^{1 *}$ \\ (1) Department of Food Science, Stellenbosch University, Private Bag X1, Matieland 7602, South Africa \\ (2) Department of Biotechnology, University of the Western Cape, Private Bag X17, Bellville 7535, South Africa
}

Submitted for publication:

Accepted for publication:

Key words: Alcaligenes; Alicyclobacillus; TAB; fruit juices; spoilage; PCR-based DGGE

\begin{abstract}
The contamination of pasteurised fruit juice products by thermophilic acidophilic bacteria (TAB) has become a concern for producers. The aim of this study was to identify the bacteria present in South African fruit juices before and after pasteurisation, using polymerase chain reaction (PCR)-based denaturing gradient gel electrophoresis (DGGE). Alicyclobacillus acidoterrestris was found to be present in apple, pear, white grape and aloe vera juice. White grape juice was found to contain Alicyclobacillus pomorum, while two uncultured bacteria in the orange, apple, mango and pear juices were presumptively identified as members of the genus Bacillus, and one uncultured bacteria was identified as being closely related to Alcaligenes faecalis. The results emphasise the need for rapid and accurate detection of TAB in food products.
\end{abstract}

\section{INTRODUCTION}

Pasteurisation temperatures of between $85^{\circ}$ and $95^{\circ} \mathrm{C}$ and the acidic nature of fruit juices (with a $\mathrm{pH}$ below 4.6) have until recently been considered sufficient to prevent the spoilage of fruit juices by bacteria and fungi (Walls and Chuyate, 1998). Cerny et al. (1984) reported the first case of spoilage of commercially available pasteurised fruit juice and found shelf-stable, aseptically packaged apple juice spoiled by the flavour compounds formed by TAB. Cases of spoilage of a number of food products due to contamination by Alicyclobacillus acidoterrestris have also been reported (Chang and Kang, 2004; Gouws et al., 2005; Walker and Philips, 2005).

Members of the genus Alicyclobacillus are rod-shaped, Grampositive, soil-borne microorganisms. These species have been shown to survive pasteurisation conditions of $95^{\circ} \mathrm{C}$ for $2 \mathrm{~min}$ and grow in a $\mathrm{pH}$ range of 2.5 to 6.0 and at temperatures between $25^{\circ}$ to $60^{\circ} \mathrm{C}$ (Deinhard et al., 1987; Jensen, 1999). The contamination of fruit juices by Alicyclobacillus spp. results in an off-flavour, a light sediment and no gas production (Splittstoesser et al., 1994). Spoilage by TAB, which can occur at any point during the process, may therefore alter the taste, colour and/or odour of the products (Chang and Kang, 2004; Walker and Phillips, 2005). Alicyclobacillus acidoterrestris causes a sour type of spoilage and produces the halophenols 2,6-dichlorophenol (2,6-DCP) and 2,6-dibromophenol (2,6-DBP), which have a medicinal and disinfectant-like smell (Jensen and Whitfield, 2003).

Molecular techniques, such as PCR-based DGGE, have proven to be reliable and rapid alternatives to conventional microbial plating (Ercolini, 2004). PCR-based DGGE analysis has been used to monitor the microbial population in various foods and beverages (Cocolin et al., 2001; Ercolini et al., 2001; Rantsiou et al., 2005).
The aim of this study was to identify the different microorganisms present in South African fruit juices and concentrates before and after pasteurisation, using PCR-based DGGE analysis.

\section{MATERIALS AND METHODS}

\section{Isolates, fruit juices and concentrates}

Pure isolates of A. acidoterrestris SA01 and A. acidocaldarius PM02 were obtained from the Food Microbiology Research Group Culture Collection (FMRGCC) at the University of the Western Cape, South Africa and served as the reference strains. These were cultivated on potato dextrose agar (PDA) (Oxoid, supplied by CA Milsch, Cape Town, South Africa) at pH 3.7 and incubated at $55^{\circ} \mathrm{C}$ for three days.

Four orange, six apple, five pear, three white grape and one aloe vera juice samples were obtained from manufacturers in the Western Cape, South Africa. Four mango juice samples were obtained from manufacturers in the Limpopo Province, South Africa. The fruit juice samples were taken directly after maceration of the fruit, after evaporation of the clear, unpasteurised juices and from the final product after pasteurisation.

\section{DNA extraction and PCR-based DGGE analysis}

The DNA was extracted and purified from colonies of the pure isolates on PDA plates and from $2 \mathrm{~mL}$ fruit juice samples using the Wizard Genomic DNA Isolation Kit (Promega, supplied by Whitehead Scientific, Cape Town, South Africa). The amplification of the V3 variable region of the $16 \mathrm{~S}$ ribosomal RNA (rRNA) gene was performed using an Eppendorf Mastercycler Personal (Merck, Cape Town, South Africa), using the primers F341 (containing the GC-clamp) and R534. These primers amplify the region between base pair 341 and 534 of the rRNA gene of E. coli (Muyzer et al., 1993), yielding 200 base pair (bp) fragments. The

*Corresponding author: e-mail address: rcwit@sun.ac.za. Tel: +27-21-808 3654, Fax: +27-21-808 3510

Acknowledgements: The National Research Foundation (NRF) South Africa, PA \& Alize Malan Trust, The Ernst and Ethel Eriksen Trust and the Brian Koeppen Memorial Scholarship (SAAFoST) are thanked for their financial support. 
primers were selected on the basis of previous successful PCRbased DGGE analyses (Garbers et al., 2004; Keyser et al., 2006). PCR reactions contained $\sim 30 \mathrm{ng}(5 \mu \mathrm{l})$ of the template DNA, $1 \mu \mathrm{l}$ of each primer $(0.5 \mu \mathrm{M}), 1 \mathrm{U}$ Taq polymerase (ABGene, supplied by Southern Cross Biotechnology, Cape Town, South Africa), $2 \mu \mathrm{ldNTPs}(200 \mu \mathrm{M})$ (Promega), $5 \mu \mathrm{l}$ of the $10 \mathrm{x}$ PCR buffer and $3 \mu \mathrm{MgCl}_{2}$ (2.5 mM) (ABGene, Southern Cross Biotechnology) in a total reaction volume of $50 \mu \mathrm{l}$.

All the PCR amplifications were initiated at $94^{\circ} \mathrm{C}$ for $5 \mathrm{~min}$. The samples were then denatured at $94^{\circ} \mathrm{C}$ for $30 \mathrm{~s}$, followed by annealing at $54^{\circ} \mathrm{C}$ for $1 \mathrm{~min}$ and elongation at $72^{\circ} \mathrm{C}$ for $1 \mathrm{~min}$, repeated for 30 cycles. A final elongation step at $72^{\circ} \mathrm{C}$ for $5 \mathrm{~min}$ was included and $5 \mu \mathrm{l}$ of the PCR products were separated on a $1.2 \%(\mathrm{~m} / \mathrm{v})$ agarose gel, containing ethidium bromide and visualised under UV light (Vilber Lourmat).

Twenty $\mu \mathrm{l}$ of the $200 \mathrm{bp}$ PCR fragments were separated using the BioRad DCode ${ }^{\mathrm{TM}}$ Universal Mutation Detection System (BioRad Laboratories). DGGE analysis was done by directly applying the PCR products onto $8 \%(\mathrm{~m} / \mathrm{v})$ polyacrylamide gels with a gradient of between 30 and $70 \%$, created by 0 to $100 \%$ denaturant, with the $100 \%$ denaturant consisting of $7 \mathrm{M}$ urea (Merck) and 40\% (v/v) formamide (Saarchem, supplied by Merck, Cape Town, South Africa). Electrophoresis was performed at a constant voltage of $130 \mathrm{~V}$ for $5 \mathrm{~h}$ at $60^{\circ} \mathrm{C}$.

\section{DNA sequencing}

Only the dominant DGGE bands were punched from the gels and directly re-amplified using the primers F341 and R534 (without the GC clamp) (Muyzer et al., 1993). DNA extracted from the fruit juices, containing only one DGGE band, was amplified using the primers F8 and R1512 (Felske et al., 1997), producing 1.5 kilobase pair $(\mathrm{kb})$ fragments. The primers amplify the region between base pair number 8 and 1512 of the rRNA gene of $E$. coli. The larger PCR products were amplified from samples containing only one DGGE band to enable more DNA sequence data to be compared to available DNA sequences in GenBank. The PCR amplification conditions and reaction volumes were as described previously.

All the PCR products were purified using Sigma Spin PostReaction Purification Columns (Sigma Aldrich, Cape Town, South Africa) as specified by the manufacturer. The PCR fragments were sequenced using the ABI PRISM 377 DNA Sequencer (Perkin Elmer) at the DNA Sequencing Facility at Stellenbosch University, South Africa. The sequences obtained were compared to $16 \mathrm{~S}$ rRNA gene sequences in the GenBank database using the BLASTn search option to determine the closest known relatives.

\section{DGGE detection limit}

A standard curve was used to determine the cell concentration of the inoculums. Cells were grown at $50^{\circ} \mathrm{C}$ for three days in yeaststarch-glucose broth (YSG broth) (Goto et al., 2002), with the $\mathrm{pH}$ adjusted to 3.7 using $2 \mathrm{~N} \mathrm{H}_{2} \mathrm{SO}_{4}$. The harvested cells were re-suspended in $9 \mathrm{~mL}$ sterile saline solution $(\mathrm{SSS})(0.85 \%(\mathrm{~m} / \mathrm{v}) \mathrm{NaCl}$ (Merck)), and a dilution series was prepared $\left(10^{-1}\right.$ to $\left.10^{-6}\right)$. The optical density (OD) was measured at $540 \mathrm{~nm}$ using a DU 530 Life Science UV/Vis Spectrophotometer (Beckman Coulter, South Africa) and correlated to colony-forming numbers of the dilutions plated on PDA (Merck) at pH 3.7.
Harvested cells of $A$. acidoterrestris were inoculated into fruit juice concentrate and into single-strength fruit juice to a concentration of $3.6 \times 10^{6}$ colony-forming units per $\mathrm{mL}\left(\mathrm{cfu} . \mathrm{ml}^{-1}\right.$ ), and a dilution series $\left(10^{-1}\right.$ to $\left.10^{-6}\right)$ was made of the inoculated fruit juice. DNA was extracted from $2 \mathrm{~mL}$ of each of the diluted fruit juices and subjected to PCR amplification, followed by separation using DGGE as described.

\section{RESULTS AND DISCUSSION}

\section{PCR-based DGGE detection limit of Alicyclobacillus acidoter- restris}

The lowest number of cells of A. acidoterrestris SA01 present in fruit juice concentrate that could be detected using PCR-based DGGE was $1.9 \times 10^{3} \mathrm{cfu}^{-\mathrm{ml}^{-1}}$. From inoculated single-strength fruit juice, the lowest number of cells of $A$. acidoterrestris that could be detected was $2.3 \times 10^{3} \mathrm{cfu}^{-1} \mathrm{ml}^{-1}$ (data not shown). Repeated detection limit determinations confirmed these results and the detection limit was similar to the detection limit $\left(10^{3}\right.$ cells. $\mathrm{ml}^{-1}$ ) found by Cocolin et al. (2000). The detection limit was determined when only $A$. acidoterrestris was present and this detection limit may be influenced when this microbe is present in mixed culture (Head et al., 1998).

The detection of low concentrations of $A$. acidoterrestris is necessary, as concentrations of $10^{3}$ to $10^{4} \mathrm{cfu}^{-\mathrm{ml}^{-1}}$ of A. acidoterrestris can lead to the formation of taint chemicals (Jensen and Whitfield, 2003). In fact, Wallis and Chuyate (1999) showed that a single spore can cause the spoilage of fruit juice under optimal conditions. PCR-based DGGE analysis can detect TAB at lower concentrations than the culture-dependent method, with a detection limit of $10^{4} \mathrm{cfu}^{-\mathrm{ml}^{-1}}$ (Pettipher et al., 1997; Gouws et al., 2005). The taste threshold of guaiacol is reportedly two parts per billion (ppb), while the halophenols 2,6-DCP and 2,6-DBP have a taste threshold of $0.5 \mathrm{ng} . \mathrm{l}^{-1}$ and $30 \mathrm{ng} . \mathrm{l}^{-1}$ respectively (Jensen and Whitfield, 2003). These taste thresholds are reached within six days at room temperature, therefore rapid detection methods are of great value to prevent the spoilage of fruit juices (Gouws et al., 2005). Furthermore, this culture-independent method offers rapid detection of spoilage organisms in fruit juices, with results obtained within two days, compared to the three to seven days needed for the incubation of selective media (Walls and Chuyate, 1998; Jensen, 1999).

\section{DGGE analysis}

\section{White grape juice}

Four pasteurised, contaminated white grape juice concentrate samples were analysed using PCR-based DGGE and the fingerprints are represented in Figure 1. Only the dominant DGGE bands were sequenced, as the shadow bands were present in too low concentrations for successful DNA sequencing. Bands $a, b$ and $\mathrm{d}$ were present in all three samples after pasteurisation and migrated at the same height in the gel as the band of the reference strain, A. acidoterrestris SA01. The bacteria represented by the DGGE band b (96\% homology, 770 out of 801 bases) and band d (94\% homology, 575 out of 608 bases) were presumptively identified as A. acidoterrestris (GenBank Accession number AB042058), based on DNA sequence analysis. These results show that the South African white grape juice was spoilt by $A$. acidoterrestris, which had survived the pasteurisation temperatures that were applied. Alicyclobacilli are soil-borne microor- 


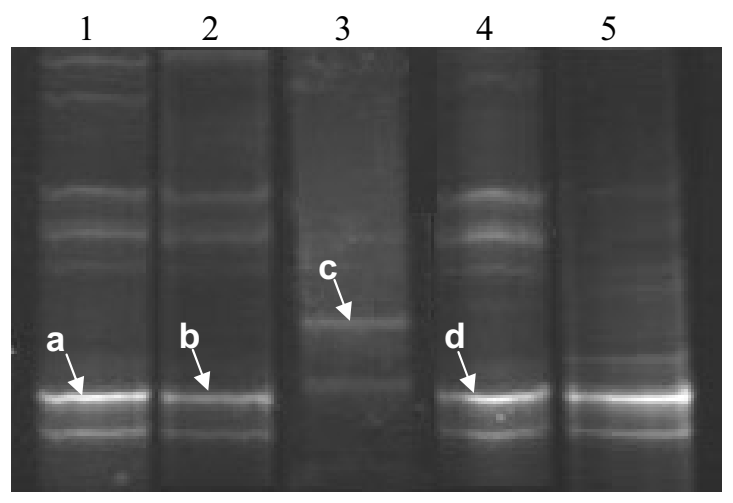

a, b, c, $\mathbf{d}$ - DGGE bands identified using DNA sequencing

FIGURE 1

PCR-based DGGE analysis of pasteurised white grape juice concentrate. Lane 1: K7; Lane 2: K13; Lane 3: K20; Lane 4: K47; Lane 5: A. acidoterrestris SA01 as reference strain.

ganisms, which have also been isolated from water. Contamination of fruit juice or concentrate usually occurs due to soil entering the processing line on the surface of the fruit (Cerny et al., 1984; Deinhard et al., 1987).

Band c was at a different position on the gel (Fig. 1) and was presumptively identified as Alicyclobacillus pomorum $(98 \%$ homology, 765 out of 778 bases) (GenBank Accession number AB089840). Alicyclobacillus pomorum has previously been isolated from a spoilt mixed fruit juice (Goto et al., 2003). It does not possess the characteristic $\omega$-alicyclic fatty acids in the cell membrane that are thought to be unique to species from this genus, but was classified within this genus based on phylogenetic relationships (Goto et al., 2003). The presence of the $\omega$-alicyclic fatty acids in the cell membrane was thought to be one of the main reasons these microorganisms survive the high temperatures of pasteurisation (Chang and Kang, 2004). The fact that this species also survived pasteurisation despite the absence of these fatty acids in the membrane indicates that other factors should also be considered as reasons for the survival.

\section{Orange, apple and pear juice}

Orange, apple and pear juices sampled before and after pasteurisation were analysed for their microbial content, and the DGGE fingerprints are presented in Figure 2. No Alicyclobacillus spp. were detected in the orange juice samples, which were pasteurised at $90^{\circ} \mathrm{C}$ for $30 \mathrm{~s}$. Band e, which was present in all three fruit juices (Fig. 2A, B and C), showed a 98\% sequence similarity to an uncultured soil bacterium from the genus Bacillus, related to B. megaterium (165 out of 167 bases identical) (GenBank Accession number AF423224). Bacillus megaterium is a Grampositive, endospore-forming bacterium isolated from soil (Vary, 1994). Soil-borne organisms enter the fruit juice production line on the surface of contaminated fruit and survive unfavourable condition in the form of endospores. The occurrence of this microbe in fruit juice is, therefore, not surprising. However, the presence of $B$. megaterium in fruit juice and its survival of pasteurisation is of concern for human health.
Band $\mathrm{f}$ was also present in all three samples analysed (Fig. 2A, $\mathrm{B}$ and $\mathrm{C}$ ). Sequence data of band $\mathrm{f}$ in the orange juice showed 94\% sequence similarity to that of an uncultured bacterium (GenBank Accession number AB184980), which was found to be closely related to Alcaligenes faecalis (158 out of 166 bases) (GenBank Accession number AM048879). Band $\mathrm{f}$ in the apple juice showed $98 \%$ sequence similarity to Alcaligenes faecalis (142 out of 145 bases) (GenBank Accession number AJ550279) and band $\mathrm{f}$ in the pear juice showed $97 \%$ sequence similarity to an uncultured bacterium from an environmental sample (GenBank Accession number DQ06862.1), also closely related to Alcaligenes faecalis (121 out of 124 bases) (GenBank Accession number AM048879). Band g below band $\mathrm{f}$ on the orange juice fingerprint showed similar results to band f ( $96 \%$ homology, 120 out of 124 bases). These multiple bands may be due to intraspecies heterogeneity of the 16S rRNA gene. Alcaligenes faecalis is a Gram-negative, aerobic, mesophilic rod, associated with the psychrotropic spoilage of raw foods. Its presence usually indicates post-process contamination.

The apple and pear juice samples represented in Figure 2B and $2 \mathrm{C}$ were contaminated with band $\mathrm{i}$. The sequence data of this band showed $99 \%$ sequence similarity to A. acidoterrestris (198 out of 200 bases) (GenBank Accession number AY573797), a strain previously isolated from fruit juice. Band i from the pear juice (Fig. 2C) is also present throughout the processing line and was presumptively identified as A. acidoterrestris (100\% homology, 192 out of 192 bases). Soil-borne organisms enter the fruit processing plant on the surface of fruit, as some fruit may drop to the ground during harvesting. Cleaning the fruit before processing may not be effective to eliminate all the contamination on the surface (Chang and Kang, 2004). Spores of A. acidoterrestris are produced at a $\mathrm{pH}$ of as low as 3.2 and have been shown to survive a temperature of $95^{\circ} \mathrm{C}$ for $2.5 \mathrm{~min}$ in orange juice (Orr and Beuchat, 2000). Should the conditions become favourable again, the spores germinate and can lead to the formation of taint chemicals, spoiling the juice (Jensen and Whitfield, 2003). Alicyclobacillus acidoterrestris spores survived pasteurisation, showing that a temperature of $85^{\circ} \mathrm{C}$ for $30 \mathrm{~s}$ was insufficient to eliminate contamination. This data confirms the presence of TAB in pasteurised South African apple and pear juices.

The fingerprints also revealed the presence of a number of unknown microorganisms, some of which could survive the pasteurisation temperatures. Band $\mathrm{h}$ was only present in the apple juice (Fig. 2B) after pasteurisation and the sequence data showed 96\% similarity to that of an uncultured Lactobacillus sp. (148 out of 154 bases) (GenBank Accession number DQ028930) related to L. plantarum (GenBank Accession number DQ239699). Lactobacillus spp. are mesophilic and cannot survive pasteurisation temperatures. This microorganism could possibly have been detected through the amplification of free DNA present in the fruit juice after the cells were destroyed during pasteurisation. Lactobacillus plantarum is a heterofermentative lactic acid bacterium and can grow at a $\mathrm{pH}$ of as low as 3.3, as found in fruit juices. It is a common food-fermenting microbe (Li et al., 2005) and has caused the spoilage of many food products, including wine and orange juice (Hays and Riester, 1952).

Sequence data for band $\mathrm{j}$ in the apple juice (Fig. 2B) showed $98 \%$ similarity to an uncultured Acetobacteraceae bacterium 


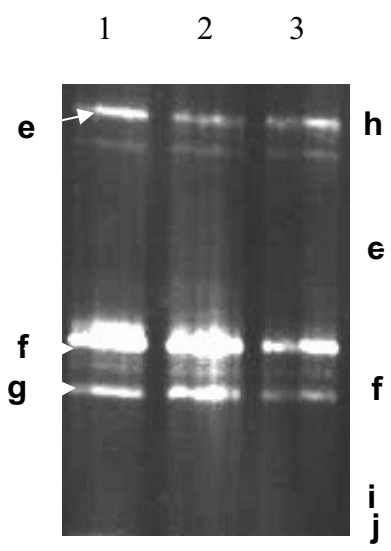

A - Orange $\begin{array}{lll}1 & 2 & 3\end{array}$

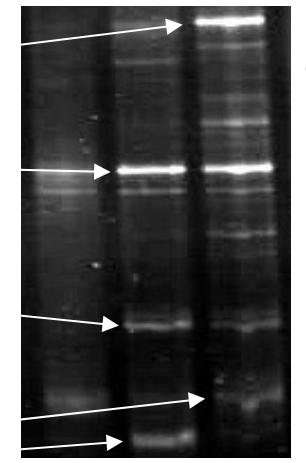

B - Apple
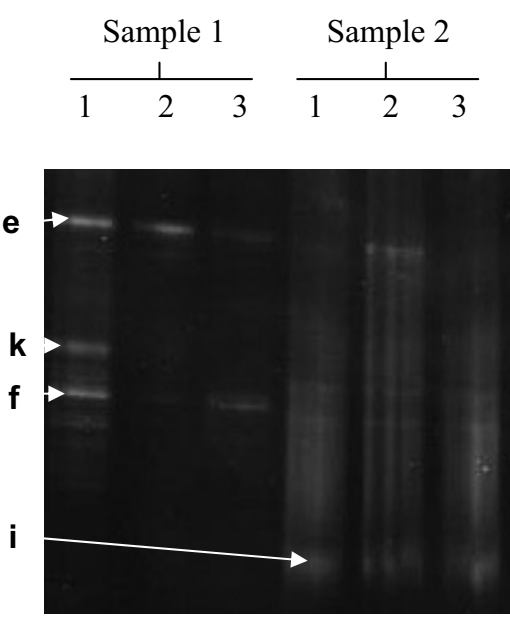

C - Pear

$\mathbf{e}, \mathbf{f}, \mathbf{g}, \mathbf{h}, \mathbf{i}, \mathbf{j}, \mathbf{k}$ - DGGE bands identified using DNA sequencing

FIGURE 2

PCR-based DGGE analysis of South African orange, apple and pear juices. Lanes 1: before pasteurisation; Lanes 2: after evaporation; Lanes 3: the final product after pasteurisation.

(142 out of 145 bases) (GenBank Accession number AY225457), related to Acetobacter pasteurianus (GenBank Accession number AB117968). This organism did not survive pasteurisation, as it is not present in the pasteurised samples. This emphasises the importance of implementing HACCP or similar regulations during food processing and of preventing the use of contaminated raw materials.

The sequence data for band $\mathrm{k}$ from the pear juice (Fig. 2C) showed sequence similarity to Enterobacteriaceae. The BLAST results showed the organism to be presumptively closely related to a Tatumella sp. (97\% homology, 135 out of 139 bases) (GenBank Accession number AJ233437). The presence of Enterobacteriaceae in food products is an indication of inadequate heat treatment or that post-process contamination from the environment has occurred. It also serves as an indication of the overall quality of food and the hygiene conditions that were present during the processing. In the pear juice it was only present in the first sample taken after maceration of the fruit, and it was absent in the samples taken after pasteurisation, indicating that the pasteurisation temperature of $85^{\circ} \mathrm{C}$ for $30 \mathrm{~s}$ was sufficient to eliminate this contaminant.

\section{Mango juice}

No bands were visible on the DGGE fingerprints of the mango fruit juice samples, either before or after pasteurisation. This could indicate that the fruit used during processing was thoroughly washed and that the pasteurisation temperature used was sufficient. However, it could also indicate that the contamination level of the mango juice was below the detection limit of the PCR-based DGGE technique. Due to the low numbers of cells, spoilage of the fruit juice might also not have occurred.

\section{Aloe vera juice}

The fingerprint of the aloe vera juice showed a band at the same position as the band of the reference strain A. acidoterrestris SA01. This was confirmed by sequencing of the $1500 \mathrm{bp}$ fragment amplified from the contaminated juice (98\% homology, 531 out of 539 bases) (GenBank Accession number AY573797). Aloe vera is a member of the Liliaceae family and has increasingly been used in health foods and for medicinal and cosmetic applications. It has been shown to have anti-tumour and anti-diabetic properties, as well as efficacy in healing wounds and burns (Loadman and Christopher, 2001). These results confirm that South African aloe vera juice is also susceptible to spoilage by TAB and that the pasteurisation temperature that is used is not sufficient to prevent spoilage. Optimum time/temperature combinations for aloe vera juice should be determined, as other constituents of the juice may be influenced by the heat treatment applied.

\section{CONCLUSIONS}

PCR-based DGGE analysis can provide a fingerprint of the bacterial community in a sample at any time during the manufacturing process and can thus be used to monitor the bacterial community during the process and identify where contamination occurs. Not only food products, but also fermented and non-fermented drinks may benefit from this molecular analysis.

\section{LITERATURE CITED}

Cerny, G., Hennlich, W. \& Poralla, K., 1984. Fruchtsaftverderb durch Bacillen: isolierung und charakterisierung des verderbserrengers. Zeitschrift für Lebensmittel-Untersuchung und -Forsuchung 179, 224-227.

Chang, S. \& Kang, D., 2004. Alicyclobacillus spp. in the fruit juice industry: History, characteristics and current isolation/detection procedures. Crit. Rev. Microbiol. 30, 55-74. 
Cocolin, L., Bisson, L.F. \& Mills, D.A., 2000. Direct profiling of the yeast dynamics in wine fermentations. FEMS Microbiol. Lett. 189, 81-87.

Cocolin, L., Heisey, A. \& Mills, D.A., 2001. Direct identification of the indigenous yeasts in commercial wine fermentations. Am. J. Enol. Vitic. 52, 49-53.

Deinhard, G., Blanz, P., Poralla, K. \& Altan, E., 1987. Bacillus acidoterrestris sp. nov., a new thermo tolerant acidophile isolated from different soils. Syst. Appl. Microbiol. 10, 47-53.

Ercolini, D., 2004. PCR-DGGE fingerprinting: Novel strategies for detection of microbes in food. J. Microbiol. Meth. 56, 297-314.

Ercolini, D., Moschetti, G., Blaiotta, G. \& Coppola, S., 2001. The potential of a polyphasic PCR-DGGE approach in evaluating microbial diversity of natural whey cultures from water-buffalo Mozzarella cheese production: Bias of "culture dependent" and "culture independent" approaches. Syst. Appl. Microbiol. 24, 610-617.

Felske, A., Rheims, H., Wolterink, A., Steckebrandt, E. \& Akkermans, A.D.L., 1997. Ribosome analysis reveals prominent activity of an uncultured member of the class Acinetobacteria in grassland soils. Microbiol. 143, 2983-2989.

Garbers, I.-M., Britz, T.J. \& Witthuhn, R.C., 2004. PCR-based DGGE typification and identification of the microbial consortium present in Kefir grains. World J. Microbiol. Biotechnol. 20, 687-693.

Goto, K., Matsubara, H., Mochida, K., Matsumura, T., Hara, Y., Niwa, M. \& Yamasato, K., 2002. Alicyclobacillus herbarius sp. nov., a novel bacterium containing $\omega$-cycloheptane fatty acids, isolated from herbal tea. Int. J. Syst. Evol. Microbiol. 52, 109-113.

Goto, K., Moshida, K., Asahara, M., Suzuki, M., Kasai, H. \& Yokota, A., 2003. Alicyclobacillus pomorus sp. nov., a novel thermo-acidophillic, endospore-forming bacterium that does not possess omega-alicyclic fatty acids, and amended description of the genus Alicyclobacillus. Int. J. Syst. Evol. Microbiol. 53, 15371544.

Gouws, P.A., Gie, L., Pretorius, A. \& Dhansay, N., 2005. Isolation and identification of Alicyclobacillus acidocaldarius by $16 \mathrm{~S}$ rDNA from mango juice and concentrate. Int. J. Food Sci. Technol. 40, 789-792.

Hays, G.L. \& Riester, D.W., 1952. The control of 'off-odor' spoilage in frozen concentrate orange juice. Food Technol. 6, 878-883.

Head, I.M., Saunders, J.R. \& Pickup, R.W., 1998. Microbial evolution, diversity, and ecology: A decade of ribosomal RNA analysis of uncultivated microorganisms. Microb. Ecol. 35, 1-21.

Jensen, N., 1999. Alicyclobacillus - a new challenge for the food industry. Food Australia 51, 33-36.
Jensen, N. \& Whitfield, F.B., 2003. Role of Alicyclobacillus acidoterrestris in the development of a disinfectant taint in shelf-stable fruit juice. Lett. Appl. Microbiol. 36, 9-14.

Keyser, M., Witthuhn, R.C., Lamprecht, C., Coetzee, M.P.A. \& Britz, T.J., 2006. PCR-based DGGE fingerprinting and identification of methanogens detected in three different types of UASB granules. Syst. Appl. Microbiol. 29, 77-84.

Li, S.-Q., Zhang, H.Q., Jin, T.Z., Turek, E.J. \& Lau, M.H., 2005. Elimination of Lactobacillus plantarum and achievement of shelf stable model salad dressing by pilot scale pulsed electric fields combined with mild heat. Innov. Food Sci. Emerging Technol. 6, 125-133.

Loadman, P.M. \& Christopher, R.C., 2001. Separation methods for anthraquionone related anti-cancer drugs. J. Chromatography 764, 193-206.

Muyzer, G., De Waal, E.C. \& Uitterlinden, A.G., 1993. Profiling of complex microbial populations by denaturing gradient gel electrophoresis analysis of polymerase chain reaction-amplified genes coding for $16 \mathrm{~S}$ rRNA. Appl. Environ. Microbiol. 59, 695-700.

Orr, R.V. \& Beuchat, L.R., 2000. Efficiency of disinfectants in killing spores of Alicyclobacillus acidoterrestris and performance of media for supporting colony development by survivors. J. Food Protect. 63, 1117-1122.

Pettipher, G.L., Osmundsen, M.E. \& Murphy, J.M., 1997. Methods for the detection, enumeration and identification of Alicyclobacillus acidoterrestris and investigation of growth and production of taint in fruit juice-containing drinks. Lett. Appl. Microbiol. 24, 185-189.

Rantsiou, K., Urso, R., Iacumin, L., Cantoni, C., Cattaneo, P., Comi, G. \& Cocolin, L., 2005. Culture dependent and independent methods to investigate the microbial ecology of Italian fermented sausages. Appl. Environ. Microbiol. 71, 1977-1986.

Splittstoesser, D.F., Churey, J.J. \& Lee, C.Y., 1994. Growth characteristics of aciduric sporeforming bacilli isolated from fruit juices. J. Food Protect. 57, 10801083.

Vary, P.S., 1994. Prime time for Bacillus megaterium. Microbiol. 140, 1001-1013.

Walker, M. \& Phillips, C.A., 2005. The effect of intermittent shaking, headspace and temperature on the growth of Alicyclobacillus acidoterrestris in stored apple juice. Int. J. Food Sci. Technol. 40, 557-562.

Walls, I. \& Chuyate, R., 1998. Alicyclobacillus - historical perspective and preliminary characterization study. Dairy Food Environ. Sanitation 18, 499-503.

Wallis, I. \& Chuyate, R., 1999. Spoilage of fruit juices by Alicyclobacillus acidoterrestris. Food Australia 52, 286-288. 